\title{
Carta-resposta ao artigo “Cesárea, aperfeiçoando a técnica e normatizando a prática: uma análise do livro Obstetrícia, de Jorge de Rezende"
}

\section{Response to the article "Cesarean sections, perfecting the technique and standardizing the practice: an analysis of the book Obstetrícia, by Jorge de Rezende"}

Tivemos conhecimento recentemente do artigo de Nakano, Bonan e Teixeira (2016) que faz diversas críticas ao prestigiado livro do professor Rezende, do qual sou autor do primeiro capítulo. Não tendo como aprofundar a análise de todo o texto pelo exíguo espaço disponível na seção de cartas, ater-me-ei ao parágrafo em que uma carta subscrita por mim e mais dois famigerados obstetras publicada no jornal $O$ Globo recebe críticas. Foi escrito entre aspas, em tom por nós considerado irônico, afirmando que considerávamos "caduca" a taxa preconizada de um limite máximo de $15 \%$ para cesarianas. Tanto era antiquado esse valor que, no mesmo ano da publicação do artigo que nos criticava, a OMS o extinguiu como parâmetro (Betran et al., 2016). Valor que não era mais respeitado em nenhum país desenvolvido do mundo. Nem mesmo naqueles com as menores taxas de cesarianas do mundo, tais como os escandinavos e a Holanda. Por conta de críticas como as nossas, que tinham como único intuito melhorar a saúde da mulher, que a OMS abandonou essa taxa.

Seguindo o texto, somos mais uma vez criticados por nossa argumentação de que o caos da saúde materna no Rio [de Janeiro] não advinha das taxas de cesarianas, mas sim do péssimo pré-natal. Que, por sinal, piorou muito do nosso editorial no jornal até hoje. O ruim virou péssimo, não havendo mais, praticamente, obstetras realizando pré-natal na rede municipal da cidade do Rio de Janeiro em gestantes de risco habitual. É muito simples comprovar isso: basta comparar taxas de mortalidades materna e neonatal nos hospitais públicos e privados. Mesmo sendo os últimos possuidores de taxas de quase 100\% de cesariana, a mortalidade é muito menor. Por último, somos criticados por ter embasado nosso argumento pela comparação com a Coreia do Sul, que tem taxas de cesarianas semelhantes às nossas, mas mortalidade materna próxima de zero. Não há o que explicar no caso, já que os números falam por si. Portanto, vemos o enfoque governamental e de grupos de pesquisa do Brasil fomentados por verba pública que querem baixar taxas de cesarianas a qualquer custo como uma cortina de fumaça para gastar menos, colocando a saúde da população em risco, e como uma forma corporativista de retirar obstetras da assistência ao parto.

A literatura científica mostra que, no nível atual do conhecimento, não há diferença entre os partos vaginal e cesariana no que se refere a desfechos importantes. Os dados para 
corroborar essa assertiva são vários e foram por nós resumidos em um estudo de revisão em que são autores os três signatários do editorial de $O$ Globo criticado aqui neste periódico (Câmara et al., 2016). Entendemos que o tema tem um potencial enorme de maniqueísmo e conflitos de interesses de todos os lados, mas é importante que as críticas sejam embasadas.

\section{REFERÊNCIAS}

BETRAN, A.P. et al.

WHO Statement on Caesarean Section Rates. BJOG, v.123, n.5, p.667-670. 2016.

CÂMARA, Raphael et al.

Cesariana a pedido materno. Revista do Colégio Brasileiro de Cirurgiões, v.43, n.4, p.301-310. 2016.
NAKANO, Andreza; BONAN, Claudia; TEIXEIRA, Luiz Antonio.

Cesárea, aperfeiçoando a técnica e normatizando a prática: uma análise do livro Obstetrícia, de Jorge de Rezende. História, Ciências, Saúde - Manguinhos, v.23, n.1, p.155172. 2016.

Raphael Câmara Medeiros Parente Universidade Federal do Rio de Janeiro.

Rio de Janeiro - RJ - Brasil 